\title{
SILENCIO PLURAL: VOCES SIN ALIENTO EN LÉVINAS, BLANCHOT Y DERRIDA
}

\author{
Sebastián Chun \\ Universidad de Buenos Aires \\ Consejo Nacional de Investigaciones Científicas y Técnicas \\ bttp://dx.doi.org/10.15304/ag.38.2.5475
}

\section{Resumen}

Desde una tradición que responde a la lógica oposicional aristotélica el silencio es considerado como único y absoluto, en su rechazo unívoco al habla. Sin embargo, sostener una frontera clara y distinta entre ambas instancias resulta problemático desde que se reconoce que el silencio es plural. Hay múltiples modos del silencio, uno de los cuales habla más que el enunciado más elocuente desde que confirma su oposición al discurso lógico y racional. Otro silencio, que aquí nos interesará analizar en detalle, es aquel que escapa al principio de nocontradicción, es decir, que habla guardando silencio y cuestionando la univocidad del sentido, para así abrir la posibilidad de pensar en otro modo de lo político. Lévinas, Blanchot y Derrida serán los nombres propios que guiarán nuestro recorrido por este frágil itinerario, que solo puede atravesarse traicionando, mediante la escritura, ese silencio aquí anunciado. Palabras clave: silencio, habla, alteridad, política, deconstrucción.

\begin{abstract}
Since the tradition that responses to the Aristotle's opositional logic, silence is considered unique and absolute as it univocally rejects speaking. Nevertheless it's problematic to hold a clear and distinct frontier between silence and speaking since one recognizes that the silence is plural. There are multiple ways of silence, one of which speaks more than the most eloquent speech, because it confirms its opposition to the logical and rational discourse. The other silence that will be analysed here in detail is beyond the non contradiction principle. In other words, this silence speaks keeping silent and questioning the only meaning in order
\end{abstract}

Recibido: 20/09/2018. Aceptado: 24/01/2019. 
to open the possibility of thinking in another way of politics. Lévinas, Blanchot and Derrida will be the proper names that will lead our travel through this fragile itinerary and the only way through is to betray by writing the silence here announced.

Keywords: silence, speech, alterity, politics, deconstruction.

Wovon man nicht sprechen kann, darüber muß man schweigen

L. Wittgenstein, Tractatus logico-philosophicus

El Pirrón argentino Macedonio Fernández, en su aforístico libro titulado Cuadernos de todo y nada, publicado póstumamente en 1972, nos deleita con la siguiente reflexión:

Bibliografía mensual de los silencios, por: El Polígrafo del Silencio.

El elogio del silencio no se puede callar y es lástima no encontrar un modo de hablar de él, con silencio. Siempre se ha reconocido que la mayor de las elocuencias es el silencio, y aunque mucho de lo que se ha hablado es por hablar bien de él, falta todavía el recurso o resorte que explique y salve este misterio de que falte un hablar que lo use y no implique la recomendación y encomio de lo que no se hace. En cuanto al Silencio, tiene a su favor escapar a esa incongruencia doblemente: no habla de él ni de la palabra.

Poca variedad ofrecen los silencios de este mes, aunque siempre mejores que el hablar sin decir nada, aunque a su vez esto no es todo fácil, pues las palabras combinan a veces tan caprichosamente que a más de uno de los autores del género no le resulta fácil no decir nada.

Lo precedente brinda un proyecto periodístico de crónica bibliográfica negativa. ${ }^{1}$

El autor de esta nota es el así llamado "Polígrafo del Silencio", seudónimo que puede interpretarse al menos de dos maneras. En primer lugar, se nombra así a quien habría escrito sobre diversas cuestiones vinculadas al silencio, tomando a este como objeto de su prolífica reflexión, convirtiéndolo en un ente a la mano disponible para ser volcado de manera mediata sobre una hoja en blanco. En segundo lugar, y he aquí la acepción para nosotros más interesante, el enigmático autor se dedicaría a la poligrafía en tanto arte de escribir de modo secreto, volviendo inteligible lo escrito solo para quien haya develado el misterio. Creando velos mediante un código extraordinario, este artista escribiría sobre el silencio sin que lo sepamos, a menos que logremos descifrar esa lengua oculta que nos evade. ¿Qué es entonces lo que inscribe en sus páginas este artífice del secreto? Una bibliografía mensual de los silencios, es decir, una suerte de catálogo de los diversos silencios que han aparecido en el último mes. Por lo tanto, podemos afirmar

${ }^{1}$ M. Fernández, Cuadernos de todo y nada, Buenos Aires, Corregidor, 2014, p. 101. 
que para Macedonio Fernández el silencio no es único, singular, indiviso, sino que existe una multiplicidad de silencios que amerita ser catalogada y reseñada con cierta periodicidad.

Pero inmediatamente se nos señala el carácter contradictorio de dicha empresa. Por un lado, hablar sobre el silencio es precisamente no poder guardar silencio, es decir, solo se puede hacer su elogio traicionándolo. Nos falta un habla que use el silencio como medio, o aún mejor, nos falta el medio que nos permita acceder al misterio de esta carencia. Por otro lado, el silencio también puede ser la mayor de las elocuencias, un modo de habla o escritura eficaz a la hora de conmover o persuadir. Por lo tanto, la crónica bibliográfica propuesta por este autor de ensueño no puede ser más que negativa, también en un doble sentido. Si se realiza mediante el habla, traiciona el objeto del cual se ocupa: el silencio. Pero si se realiza mediante el silencio, se corre el riesgo de la mayor verborragia. Y es aquí donde aparece otro Silencio, con mayúsculas, el cual no habla de él ni de la palabra. Esto no quiere decir que no hable de nada, sino que este otro Silencio no se tendría ni a sí mismo ni a su contrario como objeto, salvándose así de la contradicción antes mencionada.

La bibliografía cierra con una decepción: los silencios del mes en cuestión ofrecen poca variedad, aunque el autor los prefiera ante el imposible "hablar sin decir nada", género arduo y esquivo debido a que la combinación de palabras siempre se autonomiza y parece proponer un sentido incluso cuando no lo hay. Fracaso del silencio cuando habla más que las palabras, fracaso de las palabras cuando no pueden evitar decir algo. ¿Qué resta? El Silencio, uno de los tantos, aquel que Macedonio Fernández ha merodeado con su literatura.

Si hemos decidido acercar, ni bien comenzado nuestro recorrido, al escritor argentino con el escéptico griego fue precisamente por su puesta en cuestión del principio de no-contradicción aristotélico. Si el silencio habla más que las palabras, si existe una multiplicidad de silencios, incluso si las palabras no están resguardadas en su univocidad, no es posible sostener una frontera única y sólida entre ser y no ser. Si existe un Silencio que habla pero escapa a la contradicción entre habla y silencio, es precisamente porque ya no está regido por la ley aristotélica, esa que en el libro IV de la Metafísica condena a todo aquel que la transgreda al campo homogéneo del silencio absoluto. ${ }^{2}$ ¿Cómo hablar afirmando y negando, o ni afirmando

${ }^{2}$ Aristóteles, Metafísica, trad. H. Zucchi, Buenos Aires, Debolsillo, 2004 (Met. IV, $1006 \mathrm{a}$ $10-25)$. 
ni negando, una misma proposición al mismo tiempo?, se pregunta Aristóteles. Solo se puede emprender tan irracional tarea mediante una phoné sin logos, ruido ininteligible que se rehúsa a aceptar la univocidad del sentido, quedando así la voz de este necio interlocutor expulsada del país de la verdad. Silencio que, si no se confunde con el vacío, sí lo hace con el terreno compartido por toda sinrazón. Desde ya que nuestro interlocutor podría optar por hablar, reconoce Aristóteles, pero ese gesto lo recluye al intransitable camino de lo imposible o, lo que es lo mismo, a la literatura. ${ }^{3}$ Esta tradición, que reconoce en el silencio una falta y una incapacidad, tiene sus raíces en la expulsión de los poetas de la polis platónica e incluso en la vía intransitable de lo que no es, no puede pensarse ni tampoco expresarse presentada en el célebre poema de Parménides. Pero así como el arte mimético es rechazado por Platón debido a su efectividad política, porque tiene la capacidad de instalar un régimen tiránico en el alma del hombre y por lo tanto también en la polis ${ }^{4}$, y así como en Parménides nos enfrentamos a una posible tercera vía ${ }^{5}$, donde los hombres bicéfalos yerran al confundir el ser con el no-ser, el silencio en Aristóteles adquiere un espesor, lenguaje sin logos que podríamos distinguir de la noche oscura o el abismo absoluto. El silencio entonces puede ser comprendido como un espacio todavía plural, porque no hay un silencio. Por ese silencio sin silencio, que escapa al habla y al mutismo, intentaremos conducirnos.

\section{Blanchot}

En 1988 se realizó en Heidelberg un coloquio sobre los "alcances filosóficos y políticos del pensamiento de Heidegger". Allí Derrida improvisó un discurso titulado luego como "El silencio de Heidegger" $"$, hablando como

${ }^{3}$ Un mayor desarrollo de la cuestión del silencio en esta misma perspectiva se encuentra en S. Chun, "Entre Blanchot y Kafka: más allá de la ley, el silencio", Revista de Filosofía, vol. 68, 2012, Universidad de Chile, pp. 167-188.

${ }^{4}$ Platón, Diálogos IV. República, trad. C. Eggers Lan, Madrid, Gredos, 1988, pp. 457497 (Rep. X, 595a-621d) .

5 Incluso siguiendo la hipótesis de Cordero, que niega la existencia de un tercer camino, podría pensarse aquí en la transitabilidad de la vía de la opinión. N. Cordero, "En Parménides, "tertium non datur»", Anais de Filosofia Clássica, vol. 1, n 1, 2007, pp. 1-13.

${ }^{6}$ J. Derrida, "Heideggers Schweigen", en Antwort. Martin Heidegger im Gespräch, Pfullingen, Neske, 1988, pp. 159-162 (trad. esp. “El silencio de Heidegger”, trad. D. Tatián, Nombres, $\mathrm{n}^{\circ} 22$, Diciembre-2008, pp. 41-44). El debate entre Gadamer, Derrida y LacoueLabarthe, del cual se extrajo este fragmento de la intervención derridiana, fue publicado en su totalidad en J. Derrida, H.-G. Gadamer, P. Lacoue-Labarthe, La conférence de Heidelberg, Paris, IMEC, 2014. 
en otras oportunidades de la herencia, pero haciendo particular referencia al difícil legado del filósofo en cuestión. Derrida afirma, a contramano de lo que en ese entonces se impuso como lo "políticamente correcto", que el silencio, como el ser, se dice de muchas formas, y sobre el quizá paradigmático silencio de Heidegger con relación a su participación política efectiva durante el "Tercer Reich", Derrida sugiere que esta ausencia de palabras $d a$ a pensar. El silencio, en este caso, es aquel que abre un porvenir para la reflexión, el que nos permite acoger lo que hay de plural en la obra heideggeriana, su imposible cierre sobre sí. Siempre se hereda una tarea, que oscila entre el respeto y la traición hacia ese legado, precisamente porque no hay una herencia, sino una multiplicidad incontable. ${ }^{7}$ Si Heidegger hubiera dado una respuesta, tranquilizadora para él y para nosotros, esa palabra se habría vuelto un silencio absoluto, noche oscura donde lo peor de la violencia habría sido, una vez más, realizado. El silencio, entonces, es entendido aquí como una apertura para el pensamiento. El habla, aquella fácil, cotidiana, predecible y normalizadora, se ve paradójicamente convertida en el silencio más radical.

Resulta explícita la referencia a Blanchot en esa conferencia, cuando la "herida del pensamiento" 8 que representan Heidegger y su vínculo con el nacionalsocialismo es nombrada. Pero Blanchot también está presente en esa distinción entre un silencio absoluto y una escritura silenciosa, más allá del discurso y el lenguaje. ${ }^{9}$ El silencio total, que se opone al habla, resulta excesivo e insuficiente a la vez, porque cierra la posibilidad de pensar a través suyo al tiempo que repone la frontera que lo separaría del discurso racional. En cambio, la escritura, esa que nos sugiere Blanchot, resulta un más allá de la ley aristotélica, silencio y noche que señalan la ausencia de un sentido, único e identificable. Silencio que se expresa mediante la huella escrita y que nos sitúa ante una inyunción, la del pensamiento. Silencio entendido como tercera vía, aquella imposible de recorrer con la fría lógica binaria como vehículo, que siempre pretende dejar a aquella del lado de la sinrazón, condenándola al destierro.

${ }^{7}$ J. Derrida, Spectres de Marx, Paris, Galilée, 1993, p. 94.

${ }^{8}$ M. Blanchot, "Notre compagne clandestine", en F. Laruelle (ed.), Textes pour Emmanuel Levinas, Paris, Jean-Michel Place, 1980, pp. 80-81 ("Nuestra compañía clandestina”, trad. I. Herrera, Anthropos, no 192-193, 2001, pp. 30-36)

9 “Ausencia-presencia es, tal vez, la marca de la escritura en Blanchot, lugar de tensión, o de presencia siempre desplazada que, entonces, deja de ser presente. Blanchot se mueve siempre "entre", en ese no-lugar entre la palabra y el silencio, lugar de suspensión e indecisión, sin centro ni cierre.” M. Cragnolini, “Temblores del pensar: Nietzsche, Blanchot, Derrida”, en Derrida, un pensador del resto, Buenos Aires, La cebra, 2007, p. 124. 
Desde esta perspectiva podemos leer en El diálogo inconcluso:

[...] hablar —esto se sabe hoy en día- es poner en juego semejante falta [i.e. la falta del sentido único], mantenerla y profundizarla para disponer de ella; pero profundizarla, también es hacer que sea siempre mayor y finalmente es ponernos, en la boca y bajo la mano, ya no la pura ausencia de los signos, sino la prolijidad de una ausencia indefinida e indiferentemente significante: designación que, incluso si lleva la nulidad, es imposible de anular. Si no fuese así, hace mucho que el silencio nos habría satisfecho a todos. Pero precisamente el silencio — la falta de signos- siempre es significante y siempre de más en relación con la falta ambigua que está en juego en el habla. ${ }^{10}$

El habla no solo explicita la falta, el vacío, el trono vacante que ningún sentido puede ocupar, sino que también se encarga de profundizar esta ausencia, manteniendo el abismo desierto. Y profundizar, aclara Blanchot, es incrementar esa falta pero también rechazar el silencio absoluto, la ausencia de signos fónicos o escritos, colocando detrás de toda marca un vacío que signifique de manera indefinida e indiferente. La ausencia de sentido queda así ligada al habla y la univocidad del mismo a determinado silencio, cuyo rechazo del significante representa una saturación del sentido, un exceso de significación, convirtiéndose así en lo que a primera vista parecía ser su contrario: el habla de poder ${ }^{11}$ El silencio vuelto palabra que comienza e impone un único sentido, el silencio que afirma y, por lo tanto, se vuelve una violencia que se ejerce sobre la llegada del extraño extranjero. Optar por el silencio, por la vía del no-ser, sería reafirmar la contraposición impuesta por la ley aristotélica: discurso racional o silencio absoluto. Lógica oposicional que sueña con quitar toda palabra posible a la phoné, cuando en realidad lo que hace es robarle la voz racional, comprendida en un sentido limitado como aquella que obedece al principio de no-contradicción. Es por esto que el silencio significa de más, porque reintroduce el logos que aquí Blanchot está buscando poner en cuestión, y el mandato impuesto por el lenguaje racional redunda en una saturación de sentido. Por eso la ausencia de signos no es suficiente: hay que hablar. Pero inmediatamente Blanchot nos recuerda que también existen dos hablas:

[...] una, habla de poder, de enfrentamiento, de oposición, de negación, a fin de reducir cualquier opuesto y para que se afirme la verdad en su conjunto como igualdad silenciosa. Otra, habla fuera de la oposición, fuera de la negación y solo afirmando,

${ }^{10}$ M. Blanchot, El diálogo inconcluso, trad. P. de Place, Caracas, Monte Avila, 1970, p. 521.

${ }^{11}$ Un excelente análisis de la relación entre lenguaje y poder en Blanchot, que culmina explicitando el carácter político de la escritura luego de vincular al autor con Derrida, se encuentra en G. Bruns, "Language and Power", Chicago Review, vol. 34, n² 2, 1984, pp. 27-43. 
pero también fuera de la afirmación, porque no dice nada más que la distancia infinita de lo Otro y la exigencia infinita que es el otro en su presencia, eso que escapa a todo poder de negar y afirmar. ${ }^{12}$

El habla también puede decirse de muchas formas, y la que persigue Blanchot es una que ponga en juego la ausencia de un sentido, un habla que se sustraiga a la ley aristotélica, una palabra que diga la imposibilidad de decir. Habla, escritura o literatura, opuesta al habla de poder o al silencio absoluto. Porque la afirmación de un único sentido se vuelve una violencia, un pólemos, una negación que sueña con imponer su verdad reduciendo toda diferencia al ámbito de la igualdad silenciosa. En cambio, el habla plural es otro silencio, es un modo de actualizar el silencio también plural, el que abre al porvenir, el que resuena desde el interior del mismo lenguaje pero al que siempre se lo traiciona desde que se obedece a su llamada. Pero esta falta es insoslayable, necesaria, si se quiere evitar una falta mayor, ya que el habla que no afirma ni niega interrumpe el ámbito de lo mismo para dar lugar a la llegada del otro, de la diferencia. ${ }^{13}$

Refiriéndose a la escritura, otro nombre para el silencio plural, en El espacio literario Blanchot afirma:

Lo que se escribe entrega a quien debe escribir a una afirmación sobre la que no tiene autoridad, que es inconsistente, que no afirma nada, que no es el reposo, la dignidad del silencio, porque es lo que aún habla cuando todo ha sido dicho, lo que no precede a la palabra, porque más bien le impide ser palabra que comienza, porque le retira el derecho y el poder de interrumpirse [...] El escritor pertenece a un lenguaje que nadie habla, que no se dirige a nadie, que no tiene centro, que no revela nada. [...] Allí donde está, solo habla el ser, lo que significa que la palabra ya no habla, pero es, se consagra a la pura pasividad del ser. ${ }^{14}$

Hay un silencio que tranquiliza, silencio absoluto que nos deja dentro de los límites claros y distintos de la tradición logocéntrica. Pero hay otro silencio, ese que puede ser llamado también habla plural o escritura, que consiste en interrumpir el reposo, girar alrededor del secreto sin develarlo, dirigirse a la alteridad reconociendo el resto inasimilable que la constituye como tal. Escribir, para Blanchot, es una tarea impuesta de manera heterónoma, desde un más allá inmemorial, y que no puede ser acabada, ya que carece de fin. La literatura es inútil, fuera del mundo conformado por

${ }^{12}$ M. Blanchot, El diálogo inconcluso, trad. cit., p. 119.

${ }^{13}$ Sobre la cuestión del silencio en Blanchot véase K. MacKendrick, Immemorial Silence, New York, Suny Press, 2001, pp. 17-31.

${ }^{14}$ M. Blanchot, El espacio literario, trad. V. Palant y J. Jinkis, Buenos Aires, Paidós, 1969 , p. 20. 
los entes a la mano y el plexo de referencias correspondiente. ${ }^{15}$ Es por esto que la escritura carece de lengua común, destinatario, autor o referente. La escritura no hace más que explicitar la ausencia de un sentido unívoco y la violencia inscripta en el olvido de esta pluralidad de voces. Pero el habla blanchotiana solo puede ser fiel al silencio que la hace posible traicionándolo, clausurando este abismo sin voz, porque reconoce que en el puro silencio se esconde la posibilidad de lo peor: la violencia absoluta ante el otro.

\section{Lévinas}

Si nos referimos a la violencia ante la alteridad no podemos dejar de lado la relación que establece Blanchot entre su escritura y el habla levinasiana. Crítico del resto de fonocentrismo que hay en esta última, pero buscando reformularla para articular así una perspectiva ética para la literatura, el pensamiento de Blanchot nos conduce a preguntarnos qué ocurre con el silencio en Lévinas. Esta ruptura, esta interrupción del encuentro en el corazón de un quiasmo, se suma a la diferencia irreconciliable entre ambos pensadores resumida por Derrida esquemáticamente en cuatro puntos: la cuestión de lo "neutro", la distancia con relación al pensamiento de Heidegger, la relación con la literatura y su respectiva práctica política. ${ }^{16}$ Aquí consideramos que la problemática del silencio atraviesa estas cuatro discrepancias y las abarca.

La desconfianza que despierta la literatura para Lévinas reside precisamente en lo neutro que allí se pone en juego, es decir, en la ausencia de una presencia que garantice la univocidad del sentido de la palabra escrita. ${ }^{17}$ El habla será para la ética levinasiana el único modo de relacionarnos sin violencia con la alteridad, en tanto instancia donde el rostro del otro se hace presente, sirviendo así de fundamento del sentido e instaurando un

${ }^{15}$ Aquí la referencia a Bataille es inevitable. "El término poesía, que se aplica a las formas menos degradadas, menos intelectualizadas, de la expresión de un estado de pérdida, puede ser considerado como sinónimo de gasto; significa en efecto, de la manera más precisa, creación por medio de la pérdida." G. Bataille, "La noción de gasto", en La conjuración sagrada. Ensayos 1929-1939, trad. S. Mattoni, Buenos Aires, Adriana Hidalgo, 2003, p. 117.

${ }^{16}$ J. Derrida, y A. David, "Derrida avec Lévinas: «entre lui et moi dans l'affection et la confiance partagée»”, Le Magazine Littéraire, n 419 (Emmanuel Lévinas), 2003/4, pp. 30-34.

${ }^{17} \mathrm{La}$ "desconfianza en la poesía” por parte de Lévinas es analizada de manera rigurosa por Leslie Hill, quien desarrolla también los puntos de encuentro con Blanchot a partir de la lectura que ambos filósofos realizan de Celan. L. Hill, “"Distrust of Poetry»: Levinas, Blanchot, Celan”, MLN, vol. 120, n 5, 2005, pp. 986-1008. 
límite contra la violencia hermenéutica de la mismidad. Ante el rostro del otro solo puedo matar o hablar, siendo la segunda opción un más allá de la tradición metafísica occidental, una suspensión del poder totalitario que busca subsumir la singularidad del otro bajo alguna instancia universal. En el habla es posible la relación con el otro en tanto otro, donde se respete el dominio que ese otro ejerce sobre los signos que produce. ${ }^{18}$ Por el contrario, en el silencio no hay ética posible, incluso en ese silencio llamado escritura. ${ }^{19}$ Leemos así en Totalidad e infinito:

Pero un mundo absolutamente silencioso al que no tuviéramos acceso a partir de la palabra, aun mentirosa, sería anárquico, sin principio, sin comienzo. [...] El mundo silencioso es un mundo que nos viene del otro [...] El silencio no es, así, simple ausencia de palabra; la palabra está en el fondo del silencio como un reír pérfidamente retenido. Es lo contrario del lenguaje: el interlocutor ha dado una señal, pero se ha desprendido de toda interpretación: este es el silencio que espanta. La palabra es para el otro un auxilio del signo emitido, una asistencia a su propia manifestación por signos, un remediar el equívoco por esta asistencia. ${ }^{20}$

El silencio, para Lévinas, nunca es tal, ya que "la palabra se pronuncia aún en el silencio". ${ }^{21}$ ¿Cuál es la diferencia entonces entre silencio y habla? Precisamente el despojarse de la soberanía hermenéutica, es decir, que en el silencio el interlocutor renuncia al derecho a preservar el significado unívoco de los signos. El silencio es el equívoco, no la ausencia de palabra, ya que un mundo absolutamente silencioso no podría ofrecerse ni siquiera como espectáculo. Para Lévinas existe un lazo indisoluble entre aparición y significación ${ }^{22}$, lo que se traduce en la imposibilidad del mutismo absoluto. Si hay mundo, hay habla, ya que el primero siempre es significante y este sentido solo puede provenir del signo que emite el otro. El silencio que rechaza Lévinas es el único posible, aquel por el cual se pierde el control sobre el significado de las señales mediante las cuales el mundo, aún silencioso, nos es dado.

En "Palabra y silencio", conferencia que dictara Lévinas en 1943 y que prefigura el trabajo desplegado en Totalidad e infinito, el silencio asume

${ }^{18}$ E. Lévinas, “L’Ontologie est-elle Fondamentale?”, en Entre nous, Paris, Grasett, 1991, pp. 13-24.

${ }^{19}$ De aquí se sigue la crítica hacia el lugar asignado por Lévinas a lo femenino dentro de su ética, cuando nos habla de un "lenguaje sin enseñanza, lenguaje silencioso, entendimiento sin palabras, expresión en el secreto" o de las "idas y venidas silenciosas del ser femenino". E. Lévinas, Totalidad e infinito, trad. D. Guillot, Salamanca, Sígueme, 2002, p. 173.

${ }^{20}$ Op. cit., pp. 113-114.

${ }^{21}$ Op. cit., p. 208.

${ }^{22}$ Op. cit., p. 116. 
otro matiz y queda del lado del imperio de lo mismo, desde que Lévinas sentencia la "inhumanidad de un mundo silencioso." 23 El problema en este trabajo no es la inaccesibilidad de un mundo sin voz, silencio imposible, sino la perspectiva ética que atraviesa al silencio posible, que presupone un habla, pero una que se acerca al diktat totalitario. El sujeto que es comprensión y poder reduce toda diferencia al ámbito de la totalidad, aislándose en el silencio monádico fruto del repliegue sobre sí. Hay palabra, pero palabra que busca expresar un pensamiento personal y universal a la vez, palabra que tiende al silencio como su máxima expresión. Es el imperio del ego en su potencia totalizadora, desde que el habla se comprende aquí ya no como la condición de posibilidad del aparecer del mundo, sino como monólogo que busca silenciar toda diferencia. ${ }^{24}$

Por otro lado, Lévinas presenta el sonido como aquel estruendo que rompe con la fosforescencia del ser.

El sonido es, pues, la gloria del acontecimiento otro: lo misterioso del ser en cuanto otro. No es su signo. El signo es una cualidad que remite a una cualidad sensible ausente, sustituyendo a esa cualidad. El sonido puede ciertamente volverse signo, pero su función original, tal como acabamos de ponerla de manifiesto, es diferente. La relación con el acontecimiento de ser al que no sustituye, del cual no es la imagen, sino simplemente la resonancia, es una relación irreductible. No puede referirse más que a la sonoridad misma del sonido. Si el elemento natural de la palabra es el sonido, es que el simbolismo de la palabra no consiste simplemente en servir de signo a unas cualidades o unos pensamientos que tengan por objeto cualidades, sino en hacer resonar la alteridad misma del sujeto. ${ }^{25}$

El oír irrumpe e interrumpe el ámbito gobernado por la luz y se expone como condición de posibilidad de toda palabra. En el lenguaje no solo hay un sentido, una designación o una referencia, sino la posibilidad de que un ser aparezca desde la exterioridad. ${ }^{26}$ Esto se da gracias al sonido sin cualificar y esta "estructura de un mundo en el que lo otro puede apare-

${ }^{23}$ E. Lévinas, "Palabra y silencio", en Escritos inéditos 2, trad. M. García-Baró y M. Huarte, Madrid, Trotta, 2015, p. 51.

${ }^{24}$ Para un análisis de los escritos inéditos de Lévinas alrededor de la expresión lingüística, poniendo el acento en la enseñanza y el Decir metafórico, véase J. Llorente Cardo, "Un diálogo antisocrático: enseñanza y lenguaje metafórico en los escritos inéditos de Emmanuel Levinas", Bajo palabra. Revista de Filosofía, II Época, n 10, 2015, pp. 249-258.

${ }^{25}$ E. Lévinas, "Palabra y silencio", en Escritos inéditos 2, trad. cit., p. 68.

26 “Cómo evitar un materialismo muy vulgar, si pensamos un vínculo entre los dos términos que no sea un movimiento del pensamiento?”. Op. cit., p. 65. Resulta más que sugerente analizar cómo Lévinas anticipa y busca salvar en este pasaje la crítica que Derrida realizará años más tarde en "Violencia y metafísica", cuando vincule la filosofía del pensador lituano al empirismo. J. Derrida, "Violence et metáphysique. Essai sur la pensée d'Emmanuel Levinas”, en L'écriture et la différence, Paris, Éditions Du Seuil, 1967, p. 125. 
cer" ${ }^{27}$ no se socavará en la música ni en la palabra significante. El signo, huella escrita, en su materialidad remite y sustituye a otra materialidad; en cambio el sonido, voz entendida como instancia pre-conceptual, mantiene una relación irreductible con el acontecimiento de ser, con el resonar del verbo. Desde ya que esta oposición toma todo su rigor cuando el lenguaje, entendido como comunicación de pensamientos pre-existentes, deriva en una concepción de la sociedad reducida a la coexistencia de individuos que participan de un fondo común de pensamiento, es decir, lo neutro. Lévinas, por su parte, encuentra en el habla, en su sonoridad, un modo de relación social inmediata entre sujetos que se encuentran uno para el otro. ${ }^{28} \mathrm{La}$ expresión, el habla que abandona la mediación cognoscitiva con el mundo, manifiesta lo que no puede darse en una relación con el otro y que lo deja intacto en su secreto. ${ }^{29}$ Pero la expresión no es solo sonido, sino también significación, una que no redunda en el recurso a una conceptualidad que desde su universalidad neutral fagocita toda particularidad. Por lo tanto, Lévinas encuentra dos hablas, que prefiguran lo que vendrá años más tarde en su itinerario filosófico: el Decir y lo Dicho. ${ }^{30}$ Ambas instancias mantienen una relación de indisociable heterogeneidad, ya que no se confunden pero tampoco pueden escindirse.

Este orden intermedio entre la sucesión de la relación intersubjetiva y la simultaneidad del orden cósmico de la luz es la fábula. La palabra como instauración del relato integra la relación intersubjetiva esencialmente temporal en la simultaneidad de un mundo; constituye esa interpretación de la sociedad y del cosmos que forma una civilización. El sonido, en lugar de manifestar la plenitud del existir, la expresa remitiendo a algo distinto de la subjetividad; el sonido se convierte en signo. ${ }^{31}$

La fábula es necesaria a la hora de conformar un orden común que desborde la relación cara a cara. Por esta razón, "la palabra comporta una mentira esencial." 32 ¿Cuál? La pretensión de alcanzar por medio de una fabulación lo inefable del otro. La palabra no puede ser sincera, no puede ser verídica, y será esta escritura mentirosa la que instaurará el orden de la igualdad, el imperio de lo neutro, el dominio de lo impersonal. ${ }^{33}$ Pero

${ }^{27}$ E. Lévinas, "Palabra y silencio", trad. cit., p. 69.

${ }^{28}$ Op. cit., p. 70.

${ }^{29}$ Ibid.

${ }^{30}$ E. Lévinas, De otro modo que ser, o más allá de la esencia, trad. Antonio PintorRamos, Salamanca, Sígueme, 1987.

${ }^{31}$ E. Lévinas, "Palabra y silencio", trad. cit., p. 73.

${ }^{32}$ Op. cit., p. 74.

33 ¿A quién se refiere Lévinas cuando describe a los defensores del "romanticismo de la vida impersonal" como "los filósofos oficiales de la otra orilla del Rin"? Recordemos que 
Lévinas nos advierte sobre la necesidad de no privilegiar ninguno de los términos. El signo se encuentra tallado en el sonido, es decir, presupone la función del símbolo en tanto modo de darse la alteridad en la interrupción del universo luminoso. ${ }^{34}$ En este sentido, será para Lévinas el Decir la condición de posibilidad de lo Dicho. En otras palabras, la estructura de rehén es primera. Pero, a su vez, "la ontología, la comprensión, el poder son condiciones del cumplimiento del ser" ${ }^{35}$, en tanto el Dicho será inseparable del Decir. La clave, para Lévinas, reside en no confundir estas instancias: la del sonido indisociable de la palabra y el silencio al que ésta última conduce.

Por lo dicho hasta aquí, podemos encontrar una interpretación del silencio análoga a la blanchotiana, pero con una perspectiva opuesta. Existen también dos modos del silencio en Lévinas: el silencio total e imposible que escapa a toda palabra o fenómeno y el silencio que se confunde con la escritura, en tanto signo que pretende expresar un pensamiento o señalar un referente, exponiéndose a la multiplicidad de sentidos posibles, mientras sucumbe ante la instauración del imperio de la racionalidad impersonal. La diferencia es que Lévinas encuentra allí la imposibilidad de la ética por una doble razón. En primer lugar, debido a que la diseminación del significado implicaría una violencia sobre el rostro que se halla por detrás de sus enunciados. En segundo lugar, porque el signo pretende borrar toda diferencia a partir del fondo común de pensamiento, en tanto la puesta en crisis de la univocidad del sentido no hace más que imponer la verdad totalitaria. Por lo tanto, ambos modos del silencio terminan siendo para el pensador lituano dos caras de la misma moneda. El silencio, la palabra o lo Dicho se oponen al habla, al Decir o el sonido, en tanto modos de manifestarse la alteridad manteniéndose al resguardo de la violencia de la luz.

Blanchot, por su parte, señala que el habla como medio no-violento de relación social implica una interrupción de la asimetría entre el otro y el ego, ya que ubica en un mismo plano al infinito y la totalidad, en tanto rostros que sostienen el sentido de sus enunciados. Es decir, el habla levinasiana, en su anhelo de presencia, vuelve su ética a una lógica de la reciprocidad, donde uno deja de ser rehén de un otro para pasar a ser su igual. En términos levinasianos, el habla estaría conformada por signos y ya no

esta conferencia se dicta en Francia en 1948 y que Lévinas le asigna a este grupo adversario unos quince años de vigencia para ese entonces, lo que nos remite a 1933. Evidentemente no está pensando en Blanchot pero sí en Heidegger como fundador de esta "escuela". Op. cit., p. 75.

${ }^{34}$ Ibid.

${ }^{35}$ Op. cit., p. 76. 
por sonidos. La escritura, sin embargo, será para Blanchot un modo privilegiado de acceso a lo otro sin reducir la distancia, ya que lo neutro puesto allí en juego no hace más que girar alrededor de un secreto denunciando la imposibilidad del acceso. ${ }^{36}$ Escritura, literatura y ética quedan así ligadas, en tanto modos de interrumpir el silencio explicitando su necesidad.

En cuanto a la práctica o el posicionamiento político efectivo de ambos autores, es necesario recordar que ante los interrogantes que abre su compromiso con las políticas del Estado de Israel, el histórico, y sus consecuencias, Lévinas tendrá respuestas frágiles. Es decir, a la hora de desplegar la relación entre ética y política, el puente tendido por el pensador lituano resultará débil y problemático. Veamos aquí cómo funcionan los dos modos del silencio antes analizados. El primero, el silencio total, lleva a un intérprete como Caygill a hablar del "silencio levinasiano" con relación al Estado de Israel, en inmediato paralelismo con el "silencio de Heidegger" ante el Estado Nacionalsocialista Alemán. ${ }^{37}$ El segundo, el silencio que, desde la propuesta derridiana, da a pensar, el silencio que dice la ausencia de respuestas fáciles a la hora de articular ética y política, resulta paradójicamente traicionado por el primero. ¿Por qué? Porque el intento de respuesta ante la pregunta por el pasaje entre ética y política reside en Lévinas en su apuesta por el Estado de Israel y el silencio consecuente con relación a sus prácticas políticas. En otras palabras, porque la filosofía levinasiana concluye en un sionismo que clausura toda perspectiva crítica sobre el Israel histórico, en particular en cuanto a su política exterior. Esto quiere decir que la pluralidad de silencios no está garantizada, sino que debe ser puesta en juego de manera deliberada. El silencio absoluto, ligado a la posibilidad de lo peor, en su solidez afirma de más. Habla de poder, que se manifiesta como discurso justificador y reconciliador, que subsume bajo su dominio la posibilidad del pensamiento. El otro silencio, ligado al habla plural, a la literatura como modo de relación con lo oscuro sin violar su ausencia, ya vimos que no tiene lugar en la ética del filósofo lituano. El silencio levinasiano, entonces, nunca puede ser interpretado como un modo de la respuesta titubeante, que busca abrir el pensamiento y evita clausurarlo mediante la palabra fácil y tranquilizadora. Y es también por esta razón que la escritura blanchotiana releva al habla de Lévinas, en tanto habla de no-poder, que deja su huella en la ausencia de sentido, de destinatario y de escritor. Iterabilidad

${ }^{36}$ Sobre la cuestión de lo neutro en Blanchot y Levinas remitimos a L. Marin, "Penser le neutre: Blanchot, Levinas", en Emmanuel Levinas 100, Bucharest, Zeta Books, 2007, pp. 297-318.

${ }^{37}$ H. Caygill, Levinas and the Political, London, Routledge, 2002, pp. 190-194. 
que sirve de condición de posibilidad de toda marca, repetición que implica siempre una diferencia. ${ }^{38}$ Silencio que podemos, a pesar de Lévinas, heredar, para pensar en una política que pueda articularse con su ética del respeto absoluto e incondicional ante la alteridad radical. Una política que no recaiga en una posición liberal ${ }^{39}$ o teológico-política, ambas formas del silencio más significante, el que impide el despliegue de ese otro que aquí llamaremos también "deconstrucción".

\section{Derrida}

Derrida abordará ese hiato entre ética y política intentando escindir dos modos del silencio, para dejar entrever el "más-allá-dentro" de la obra levinasiana también.

La paz, como el silencio, es la extraña vocación de un lenguaje llamado fuera de sí por sí. Pero como el silencio finito es también el elemento de la violencia, el lenguaje no puede jamás sino tender indefinidamente hacia la justicia reconociendo y practicando la guerra en sí. Violencia contra violencia. Economía de violencia. ${ }^{40}$

El habla siempre es violencia, en tanto la universalidad del concepto no puede nunca dejar de intentar borrar todo resto de singularidad de la cosa nombrada, ahora convertida en mera particularidad. Pero el lenguaje es plural, en tanto puede asumir como tarea esa búsqueda de una relación de apertura incondicional ante el otro, es decir, la justicia. Y este esfuerzo por desbordar, mediante el lenguaje, los límites impuestos por él, nos conduce a soñar con un silencio que no sea la contracara del discurso lógico. Sin embargo, este silencio infinito, que habla pero sin imponer un sentido, se confunde con lo peor de la violencia, el silencio finito excesivamente significante. Si el silencio también es plural, optar por aquel que no satura un único sentido redunda en una traición al silencio, ya que solo se puede tender hacia él mediante el lenguaje. Gesto aporético que ha vinculado desde siempre la deconstrucción con la teología negativa, aunque no se confunde con ella. Leemos en la célebre conferencia "Cómo no hablar. Denegaciones":

${ }^{38}$ J. Derrida, "Signature, événement, contexte", en Marges de la Philosophie, Paris, Minuit, 1972, pp. 365-393.

${ }^{39}$ Encontramos un riguroso análisis de la cuestión del liberalismo en el pensamiento político de Lévinas en Herzog, A., "Is Liberalism "All We Need»?: Lévinas's Politics of Surplus", Political Theory, vol. 30, No 2, April 2002, pp. 204-227.

${ }^{40} \mathrm{~J}$. Derrida, "Violence et metáphysique. Essai sur la pensée d’Emmanuel Levinas", en L'écriture et la différence, ed. cit., p. 172. 
Un ser consciente es un ser capaz de mentir, de no presentar en un discurso aquello de lo que tiene sin embargo la representación articulada: aquel que puede evitar hablar. Pero para poder mentir, posibilidad segunda y ya modalizada, primero hace falta, posibilidad esta más esencial, ser capaz de guardar para sí, diciéndoselo, aquello que ya se sabe. [...] Pero este guardar-para-sí, esta disimulación para la que hace falta ya ser varios y diferir de sí mismo, supone también el espacio de una palabra prometida, es decir, una huella cuya afirmación no es simétrica. [...] Simplemente la no-manifestación no está asegurada jamás. ${ }^{41}$

Callar es imposible, no existe modo de guardar silencio, precisamente por el carácter plural del mismo. Pero si el silencio que abre la posibilidad de acoger incondicionalmente al otro en su singularidad absoluta no se distingue con claridad del silencio totalitario, ¿cómo estar seguros de que el silencio presente no continúa siendo significante? Evitar hablar implica ya haber dado respuesta a una llamada previa, una promesa anterior que sirve de inyunción y nos ordena ser responsables ante el otro. Si siempre se es ya rehén del otro, es porque la huella nos precede y el silencio nunca está asegurado. ¿Qué nos queda entonces? Hablar, pero reconociendo el carácter violento de nuestra palabra y practicando una economía de violencia en vistas a esa hospitalidad incondicional huidiza. Tendemos al silencio infinito mediante un habla que traiciona el silencio, para así evitar el silencio finito o absoluto. Incluso si sostenemos que "no hay que hablar", esto implica una relación con la alteridad signada por el habla, estructura de rehén ineludible.

En el lugar de cruce de esos dos lenguajes, de los que cada uno sostiene el silencio del otro, un secreto debe y no debe dejarse divulgar. Puede, no puede. Hay que no divulgar pero hay también que hacer saber o más bien hacer saber ese "hay que", "no hay que", "hay que no". ${ }^{42}$

Aquí nos encontramos con la lectura que hace Derrida del célebre final del Tractatus logico-philosophicus de Wittgenstein ${ }^{43}$, que prescribe un "deber ser" silencioso: "De lo que no se puede hablar hay que callar (Wovon man nicht sprechen kann, darüber muß man schweigen)". ${ }^{44}$ Una lectura superficial de esta sentencia nos conduce a un límite absurdo. ¿Por qué? Porque aquello de lo que no se puede hablar pareciera tener el silencio

${ }^{41}$ J. Derrida, "Cómo no hablar. Denegaciones”, en Psyché. Invenciones del otro, trad. P. Peñalver, Avellaneda, La cebra, 2017, p. 637.

${ }^{42}$ Op. cit., p. 644.

${ }^{43}$ Henry Staten desarrolla el vínculo entre Derrida y lo que llama el periodo "deconstructivo" de Wittgenstein en H. Staten, Wittgenstein and Derrida, Nebraska, University of Nebraska Press, 1984.

${ }^{44}$ L. Wittgenstein, Tractatus logico-philosophicus, trad. J. Muñoz e I. Reguera, Madrid, Alianza, 2010, p. 132. 
asegurado. ¿Cómo podría existir el deber de hacer algo que se impone de manera heterónoma e implacable? Y es esta la razón por la cual Derrida destaca el "hay que $(m u \beta)$ ", el cual "inscribe el mandato de silencio en la orden o la promesa de un «hay que hablar»" ${ }^{45}$ Algunas traducciones castellanas pierden este punto al traducir "mejor es callarse". No es una cuestión de valores, mucho menos de opciones, hay un deber, un imperativo, una norma que debe respetarse. Por lo tanto, debe existir la posibilidad inversa, el mandato que nos convoca a hablar de aquello que no se puede hablar. Desde ese momento, las fronteras se pierden y no se puede asegurar que el silencio no sea aún un modo del habla. Si hay que hacer silencio es porque se puede hablar sobre aquello que repele al habla, por lo tanto, el silencio corre el riesgo de ser una modalización de la palabra.

Unas líneas más arriba en el Tractatus, específicamente en las observaciones al sexto aforismo, el filósofo austríaco afirma que "lo inexpresable, ciertamente, existe. Se muestra, es lo místico (Es gibt allerdings Unaussprechliches. Dies zeigt sich, es ist das Mystische)." ${ }^{46}$ Toda pregunta formulable tiene también una respuesta formulable, es decir, no hay secreto o enigma para Wittgenstein. Lo que debe hacer la filosofía es precisamente reconocer su límite, no hablar sobre aquello que no se puede ni siquiera preguntar. Para la relación inmediata con ese más allá del lenguaje queda reservada la experiencia mística, la cual no debe ser traducida en palabras, tarea por demás imposible. Aquí nos enfrentamos de lleno con el problema de la teología negativa y su distancia con relación al pensamiento de Derrida. El silencio de la mística evoca una hiper-esencialidad, para la que se reserva una relación inmediata, sin concepto. La ausencia de palabra, entonces, refiere a una saturación de sentido, una completitud desbordante que se vuelve inabarcable para todo significante. Callar resulta luego ser un deber, un respeto hacia la verdad que se mantiene como referente absoluto de la huella que se borra. Por el lado de la deconstrucción, el silencio plural es la condición de posibilidad de toda huella, es decir, la différance que en su juego arbitrario y relacional produce los efectos de positividad de cualquier signo o experiencia posibles. Hay simulacro de sentido, porque este se disemina en su inestabilidad y contingencia, desde que la escritura deja de ser pensada como un suplemento de la voz. ${ }^{47}$

\footnotetext{
${ }^{45}$ J. Derrida, "Cómo no hablar. Denegaciones”, trad. cit., p. 631.

${ }^{46}$ L. Wittgenstein, Tractatus logico-philosophicus, trad. cit., p. 131.

${ }^{47}$ J. Derrida, "La différance", en Marges de la Philosophie, ed. cit., pp. 1-29.
} 
Pero si el silencio impuesto por Wittgenstein parte de un deber, de una "hay que", Derrida entiende que esto se debe a la estructura de promesa inscripta en el habla y en el silencio como modalidad del habla, desde que mi relación con el otro es previa a la constitución de un "yo". ${ }^{48} \mathrm{La}$ estructura de rehén es primera, es decir, la apertura incondicional ante la singularidad absoluta de un otro es anterior y constitutiva de cualquier identidad, volviéndonos así responsables ante un imperativo que viene del otro y que nunca podemos asumir como propio.

Ya no es cuestión de no decir. Incluso si se habla para no decir nada, incluso si un discurso apofático se priva de sentido o de objeto, tiene lugar. Aquello que lo ha lanzado o lo ha hecho posible ha tenido lugar. La eventual ausencia del referente alude todavía, si no a la cosa de la que se habla [...] sí al menos al otro (otro que el ser) que llama o a quien se destina esta palabra, incluso si ésta le habla por hablar o para no decir nada. Como este llamamiento del otro ha precedido ya siempre a la palabra, a la cual, en consecuencia, aquel no ha estado jamás presente una primera vez, ese llamamiento se anuncia por anticipado como una llamada. Tal referencia al otro habrá siempre tenido lugar. ${ }^{49}$

Aquí, como en Macedonio Fernández, aparece el aporético hablar sin decir nada, género imposible desde que la llamada del otro es siempre previa a todo gesto, incluso el de guardar silencio. Por lo tanto, el lenguaje debe reconocerse como violencia pero, en ese mismo gesto, volverse sobre sí para encontrar la alteridad que escapa a todo presente y que hace posible cualquier experiencia. De este modo, el habla da lugar al silencio que rige en el corazón oculto de toda huella, resto inapropiable que pone en cuestión la seguridad de mi hogar, extraño extranjero que ya nos ha visitado y a quien recibimos incondicionalmente antes de todo logos. Desde este silencio, desde este modo del silencio, se abre la posibilidad de pensar lo imposible mismo, un modo de lo político que interrumpa el diálogo hipócrita liberal. Más allá del intercambio de sentidos entre sujetos libremente dispuestos en el espacio social, escena que obtura la violencia constitutiva de esta distribución de roles, Derrida nos invita a pensar una política atravesada por el silencio: la democracia por venir.

Leemos en Políticas de la amistad, con relación al peligroso quizá nietzscheano:

En cada instante el discurso se eleva hasta el límite, al borde del silencio: se traslada más allá de él mismo. Se ve arrastrado por la extrema oposición, la alteridad, por la hipérbole que lo involucra en una sobrepuja infinita (más libre que la libertad del

${ }^{48}$ Op. cit., p. 634.

${ }^{49}$ Op. cit., p. 647. 
espíritu libre, mejor demócrata que la masa de los demócratas modernos, aristócrata entre todos los demócratas, más futuro y futurista que el moderno), arrastrado por el quizá que viene a indecidir el sentido en cada momento decisivo. ${ }^{50}$

El habla encuentra un más allá dentro suyo gracias al silencio que sirve de condición de posibilidad de toda palabra, transgresión de un límite o frontera que no separa de nada más que de esa alteridad constitutiva de todo mismo, oposición fantasmática que vuelve a cualquier decisión una decisión del otro en mí. Locura o sinrazón de un habla silenciosa, si reducimos lo racional al logos que obedece ciegamente al orden binario aristotélico. Y es esta "contra-cultura del saber-callarse" ${ }^{1}$, este peligroso quizá, el que abre otro camino posible para pensar lo político, desde ese silencio que "no es otra cosa que una cierta forma de hablar: secreta, discreta, discontinua, aforística, elíptica." 52 ¿Qué tipo de unidad política se puede construir sobre el silencio plural? Claramente nunca una liberal, cuyo principio rector es el de la transparencia dialógica, ni tampoco una fundada en el silencio absoluto, anhelo totalitario por excelencia.

No son solidarios, estos dos, son solitarios, pero se alían en silencio sobre la necesidad de callarse juntos, cada uno por su lado sin embargo. Lazo social, contemporaneidad, quizá, pero en la común afirmación de la des-conexión, en el estar-solo intempestivo y, simultáneamente, en la aquiescencia conjunta de la desunión. ${ }^{53}$

Comunidad sin comunidad es un nombre que Derrida no acuñará para esta relación sin relación entre los amantes de la soledad. Política de la separación construida sobre una distancia que reúne en el silencio, señalando la insociable sociabilidad que sirve de fundamento abismal de todo orden político, diferencia estructural que debe ser confesada para así evitar las peores consecuencias de su ocultamiento. Porque sabemos que lo reprimido siempre retorna y nunca de la mejor manera. Pero "no todos los silencios consuenan" 54 , porque el callarse entre amigos se sustrae a cualquier medida común que pretenda homogeneizar la diferencia. El hacer silencio juntos en la desconexión, en la intempestividad de un encuentro imposible y la desunión conjunta implica un resto imborrable que vuelve al silencio plural. Dentro de esta multiplicidad Derrida privilegiará ese silencio que se confunde con el habla blanchotiana, en cuanto resiste a la oposición entre el silencio absoluto y el habla locuaz. Silencio que dice la ausencia de sentido

\footnotetext{
${ }^{50}$ J. Derrida, Políticas de la amistad, trad. P. Peñalver, Madrid, Trotta, 1998, p. 60.

${ }^{51}$ Op. cit., p. 71.

${ }^{52}$ Op. cit., p. 72.

${ }^{53}$ Op. cit., p. 73.

${ }^{54}$ Op. cit., p. 76.
} 
unívoco, de sistema total, de mismidad replegada sin resto sobre sí. Silencio que siempre es un hacer justicia ante la llegada de cualquier/absolutamente otro (tout autre est tout autre) y que abre la posibilidad de pensar en otro modo de lo político, más allá del sacrificio teológico-político y la transparencia mortífera liberal.

\section{Conclusiones}

En el artículo que aquí finaliza, esperando dar lugar al fundamental murmullo inaudible que acompaña a toda reflexión, intentamos hacer resonar las distintas modalidades del silencio. Si bien las que aquí presentamos se oponen a priori al habla y su anhelo de significación unívoca, encontramos que existe un silencio que se vuelve signo de un significado con pretensiones de plenitud, como si soñara con extremar las virtudes de la voz hasta alcanzar una verdad absoluta, total, que borre con su presencia muda toda diferencia. Así hallamos que este silencio es el peor de los caminos posibles, porque no solo recupera la lógica oposicional aristotélica sino que conduce a una perspectiva política que borra toda alteridad bajo el imperio absoluto de una universalidad homogeneizadora. Por esto, gracias a los autores aquí visitados, donde Blanchot y Derrida heredan el pensamiento de Lévinas pero distanciándose en cuanto a la heterogeneidad del silencio, nos propusimos pensar otro silencio, ese que rehúye a la ley del filósofo y nos permite pensar en un modo de relación con el otro más allá de la transparencia de la traducción. Silencio que habla explicitando la violencia inscripta en él, gesto que nos permite llamarlo escritura o también literatura. Tal vez Macedonio Fernández, al que Borges refiere como "ejercitado en el silencio" ${ }^{55}$, haya visto antes que muchos esta relación entre la literatura y el silencio plural.

Silencio, de cuyo texto, fácil de recordar y del cual el Hablar es la única errata posible, el procedimiento de cita no ha sido hasta hoy encontrado. [...] El esfuerzo feriado de páginas en blanco que hemos leído tantas veces dispersas en la foliación de libros, ocasionándonos la única perplejidad posible y privativa a la especie lectora, esas ocho o diez páginas de heroísmo de autor y que el lector, en ella tergiversado, sostendrá siempre que no las compró, que no injuriaban su pensamiento de compra; ese esfuerzo, señores, de transcripciones del silencio, banal aunque de buen anhelo y presentimiento, era capitulación del poder de la palabra. Para la literatura es una claudicación confesarse incapaz de expresar con palabras el silencio y acogerse a

${ }^{55}$ J. L., Borges, "La lírica argentina contemporánea”, Cosmópolis, n 36, Madrid, Diciembre de 1921. Luego publicado en Textos recobrados (1919-1929), Bs. As, Emecé, 1997, p. 132. 
las páginas en blanco. La imitación literaria del silencio era la sola digna de nuestra profesión; es por fin lo técnico en el asunto. ${ }^{56}$

La página en blanco, nunca suficiente, es aquí referida como el lugar donde asoma ese silencio que corre por debajo de toda huella, terreno inestable y fugaz donde se erigen las estructuras significantes que componen el libro en su búsqueda por imitar ese silencio plural. Y es este el que asedia esa misma estructura, desde que el valor de cada signo, su positividad, no reside en una sustancia o una presencia, sino en el juego de diferencias que se establece entre los distintos elementos del sistema, relación muda que no encuentra un nombre propio que nos permita designarla. ${ }^{57}$ La différance es el modo que aventura Derrida para (no) hablar de este espaciamiento constitutivo de toda marca, reconociendo la imposibilidad de romper con el anonimato de ese intervalo.

Leemos en Salvo el nombre, el otro gran texto que Derrida dedica a la teología negativa:

Hablamos aquí en y sobre un lenguaje que, al tiempo que abierto por la ferencia, expresa la inadecuación de la referencia, la insuficiencia o el fallo del saber, su incompetencia en lo que respecta a aquello de lo que se dice saber. [...] Y el lenguaje de la ab-negación o del renunciamiento no es negativo: ello, no solo porque no enuncia a la manera de la predicación descriptiva y la proposición indicativa simplemente afectada por una negación ( «esto no es aquello»), sino porque denuncia en igual medida que renuncia; y denuncia conminando, prescribe desbordar esa insuficiencia, ordena: hay que hacer lo imposible, hay que ir (Geh, jve!) adonde no se puede ir. [...] Allá, hacia el nombre, hacia el más allá del nombre en el nombre. Hacia lo (aquel o aquella) que resta - salvo el nombre. ${ }^{58}$

De este modo el pensamiento de la différance rechaza la interpretación corriente del primer Wittgenstein. ${ }^{59}$ De lo que no se puede hablar es de lo único que se debe hablar. ¿Por qué? Porque así se abre la posibilidad de pensar en otro modo de relacionarnos con la alteridad, más allá de la apropiación a la que conlleva la tradición carnologofalocéntrica. Pensar lo imposible es lo único que queda por hacer, tarea inaudita, silenciosa, que sueña con esa política por venir.

\footnotetext{
${ }^{56}$ M. Fernández, Papeles de Recienvenido y Continuación de la Nada. Obras Completas, volumen IV, Buenos Aires, Corregidor, 2007, p. 54.

${ }^{57}$ J. Derrida, "La différance", en Marges de la Philosophie, ed. cit., pp. 1-29.

${ }_{58}^{5}$ J. Derrida, Salvo el nombre, trad. H. Pons, Buenos Aires, Amorrortu, 2011, pp. 51-52.

${ }^{59}$ J. Derrida, “Cómo no hablar. Denegaciones”, trad. cit., p. 631.
} 


\section{Bibliografía}

Aristóteles, Metafísica, trad. H. Zucchi, Buenos Aires, Debolsillo, 2004. Bataille, Georges, "La noción de gasto", en La conjuración sagrada. Ensayos 1929-1939, trad. S. Mattoni, Buenos Aires, Adriana Hidalgo, 2003.

Blanchot, Maurice, El espacio literario, trad. V. Palant y J. Jinkis, Buenos Aires, Paidós, 1969.

Blanchot, Maurice, El diálogo inconcluso, trad. P. de Place, Caracas, Monte Avila, 1970.

Blanchot, Maurice, "Nuestra compañía clandestina”, trad. I. Herrera, Anthropos, $\mathrm{n}^{\circ}$ 192-193, 2001, pp. 30-36.

Borges, Jorge Luis, "La lírica argentina contemporánea”, Cosmópolis, $n^{\circ}$ 36, Madrid, Diciembre de 1921 (Textos recobrados (1919-1929), Bs. As, Emecé, 1997)

Bruns, Gerald, "Language and Power", Chicago Review, vol. 34, n² 2, 1984, pp. 27-43.

Caygill, Howard, Levinas and the Political, London, Routledge, 2002. Chun, Sebastián, "Entre Blanchot y Kafka: más allá de la ley, el silencio", Revista de Filosofía, vol. 68, 2012, Universidad de Chile, pp. 167-188. Cordero, Nestor, "En Parménides, «tertium non datur»", Anais de Filosofia Clássica, vol. 1, n 1, 2007, pp. 1-13.

Cragnolini, Mónica B., "Temblores del pensar: Nietzsche, Blanchot, Derrida”, en Derrida, un pensador del resto, Buenos Aires, La cebra, 2007.

Derrida, Jacques, "Violence et metáphysique. Essai sur la pensée d'Emmanuel Levinas", en L'écriture et la différence, Paris, Éditions Du Seuil, 1967.

Derrida, Jacques, "Signature, événement, contexte", en Marges de la Philosophie, Paris, Minuit, 1972.

Derrida, Jacques, "La différance", en Marges de la Philosophie, Paris, Minuit, 1972.

Derrida, Jacques, “El silencio de Heidegger”, trad. D. Tatián, Nombres, $n^{\circ} 22$, Diciembre-2008, pp. 41-44.

Derrida, Jacques, Spectres de Marx, Paris, Galilée, 1993.

Derrida, Jacques, Políticas de la amistad, trad. P. Peñalver, Madrid, Trotta, 1998.

Derrida, Jacques y David, Alain, “Derrida avec Lévinas: «entre lui et moi dans l'affection et la confiance partagée»", Le Magazine Littéraire, $\mathrm{n}^{\circ}$ 419 (Emmanuel Lévinas), 2003/4, pp. 30-34. 
Derrida, Jacques, Salvo el nombre, trad. H. Pons, Buenos Aires, Amorrortu, 2011.

Derrida, Jacques; Gadamer, Hans-Georg; Lacoue-Labarthe, Philippe, La conférence de Heidelberg, Paris, IMEC, 2014.

Derrida, Jacques, "Cómo no hablar. Denegaciones", en Psyché. Invenciones del otro, trad. P. Peñalver, Avellaneda, La cebra, 2017.

Fernández, Macedonio, Papeles de Recienvenido y Continuación de la Nada. Obras Completas, volumen IV, Buenos Aires, Corregidor, 2007. Fernández, Macedonio, Cuadernos de todo y nada, Buenos Aires, Corregidor, 2014.

Herzog, Annabel, «Is Liberalism «All We Need»?: Lévinas's Politics of Surplus", Political Theory, Vol. 30, No 2, April 2002, pp. 204-227. Hill, Leslie, "«Distrust of Poetry»: Levinas, Blanchot, Celan", MLN, vol. $120, \mathrm{n}^{\circ} 5,2005$, pp. 986-1008.

Lévinas, Emmanuel, "L'Ontologie est-elle Fondamentale?", en Entre nous, Paris, Grasett, 1991, pp. 13-24.

Lévinas, Emmanuel, De otro modo que ser, o más allá de la esencia, trad. Antonio Pintor-Ramos, Salamanca, Sígueme, 1987.

Lévinas, Emmanuel, Totalidad e infinito, trad. D. Guillot, Salamanca, Sígueme, 2002.

Lévinas, Emmanuel, "Palabra y silencio", en Escritos inéditos 2, trad.

M. García-Baró y M. Huarte, Madrid, Trotta, 2015.

Llorente Cardo, Jaime, "Un diálogo antisocrático: enseñanza y lenguaje metafórico en los escritos inéditos de Emmanuel Levinas", Bajo palabra. Revista de Filosofía, II Época, n 10, 2015, pp. 249-258.

MacKendrick, Karmen, Immemorial Silence, New York, Suny Press, 2001.

Marin, Laura, "Penser le neutre: Blanchot, Levinas", en Emmanuel Levinas 100, Bucharest, Zeta Books, 2007, pp. 297-318.

Platón, Diálogos IV. República, trad. Eggers Lan, C., Madrid, Gredos, 1988.

Staten, Henry, Wittgenstein and Derrida, Nebraska, University of Nebraska Press, 1984.

Wittgenstein, Ludwig, Tractatus logico-philosophicus, trad. J. Muñoz e I. Reguera, Madrid, Alianza, 2010. 